\title{
The paradigm and the pendulum
}

\author{
All hail the new Dark Ages.
}

\section{William K. Hartmann}

M y grandfather used to tell me stories about the Old Days. After the Chinese landed on the Moon, the Americans started this crash program to go to Mars. But when they started stopping off at asteroids on the way, they decided that asteroids were more valuable. They claimed some of them were made of pure iron. My grandfather was on one of the prospecting crews that flew to one of them, number 3341 he called it. They thought it had metals, but it turned out to be one of the uninteresting ones. He told me he never went back, but he did spend time at the research station on Mars until they closed it down. In private, he still claimed they had found microbes under the permafrost, in spite of the scriptural counter-arguments.

He thought people in his generation were heading into a golden age, because they were moving mineral extraction industries into space and powering them by solar energy, and reducing the levels of twentieth-century pollution on Earth. He said something about cutting the $\mathrm{CO}_{2}$ emissions, which they used to claim were the cause of the ice caps melting. Of course, as we know today, it was all based on secular hubris, funded by big government programs that used taxes to benefit university intellectuals.

The problem was that the scientists and academics appealed to so-called facts instead of common sense and faith. They tried to indoctrinate children with godless liberal ideas. For example, they claimed that the Earth was 4.5 billion years old, which we now know to be a mistake due to trusting isotopes that were put in the ground by Satan. They also claimed that humans could build intelligent machines, that life had been created beyond Eden on Mars, and that planets had been discovered around other stars - ideas that would make Earth and humanity merely a random part of nature, instead of the centerpiece of Creation. Fortunately, common sense began to prevail when the US Senate cut off the funding for this type of research and removed these ideas from school curricula.

The cut-off of public funding to secular humanist universities and science foundations proved that those once-coddled institutions couldn't compete in the modern market-place. The resulting tax cuts, and the institution of free-enterprise-based funding of scholars through approved Think Tanks, ushered in our new Fundamentalist Age. The corrupting influence of 'secular science' has been well documented. For example, there

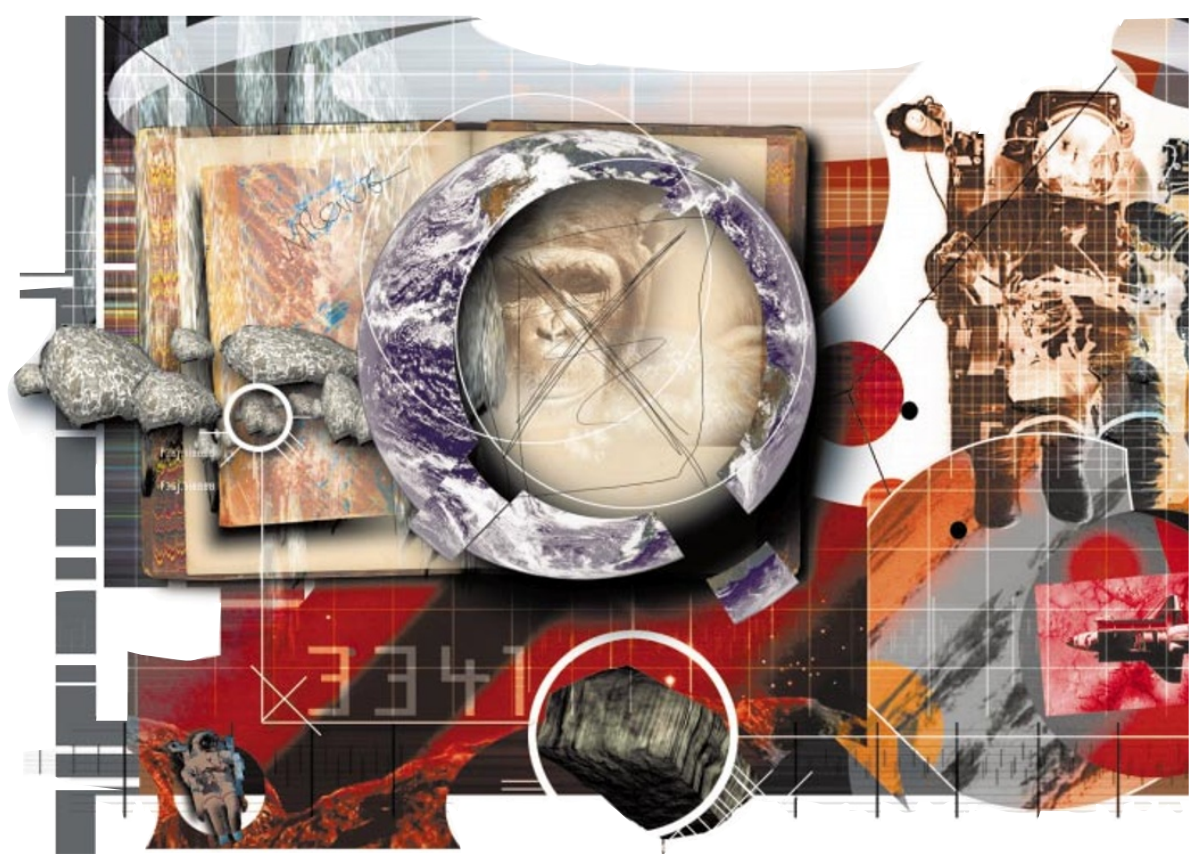

were attempts to redistribute the natural diversities in wealth, reduce population, teach children that men were related to apes, and encourage women to participate in public life. The Lord rendered his judgement on these evils in the 2050s by sending famines and plagues. With the world-wide Jihad against the scientific method, we survivors have gained the Lord's approval once again. That is why people like my grandfather had to be sequestered, both for their own good and for the good of civilization.

David (aged 19). Admissions essay for the George Will Think Tank, 2063.

I he end of the scientific era began in the United States around 2000, when fundamentalist political forces allied themselves with anti-environmentalist international corporate interests, and began to attain electoral majorities, due to splintering of the political centre. Starting with control of local school districts, they eventually captured the national government. This success encouraged fundamentalism in Europe and Asia.

All these forces shared a revulsion against what they regarded as the corrupting spread of humanistic thinking associated with the scientific method, which had promoted unpopular new data about biological evolution, the plurality of worlds, species extinctions and global climate change. In various countries this political alliance terminated the funding of traditional scientific research and destroyed a number of libraries and databases. This, in turn, ended the fledgling efforts to deal with environmental, health, and population issues, and to establish human capability in space.

Since the decline of the fundamentalist movement, new research has supported some of the once-ridiculed twentieth-century work. Isotopic work at the University of Iceland has reaffirmed the great antiquity of Greenland rocks and the purported lunar rock samples. Resources of solar-based energy and asteroidal metals reported in the 2020 s, if confirmed, could help to re-establish a vibrant technology-based civilization.

But many scholars argue that it is too late: the destruction of the global scientific infrastructure, coinciding with the near-exhaustion of easily accessible terrestrial resources in the mid-twenty-first century, effectively prohibits humanity from achieving a second industrial revolution or becoming an interplanetary culture. In this view, we are now imprisoned on Earth forever.

Report on the New Science, UNESCO II conference, Spitsbergen, June 2100.

Planetary scientist William K. Hartmann was the first winner of the Carl Sagan Medal of the American Astronomical Society (1998). His current novel, Mars Underground (Saint Martin's Press), deals with government control of science and is the basis for some of the history described here. 